\title{
Dual-Polarized Printed S-Band Radar Array Antenna for Spacecraft Applications
}

\author{
R. Di Bari, T. Brown, Member, IEEE, S. Gao, Member, IEEE, M. Notter, D. Hall, and C. Underwood, Member, IEEE
}

\begin{abstract}
A novel dual-polarized broadband antenna array for S-band is presented. This antenna is composed of $6 \times 2$ microstrip antenna elements with a hybrid feed-line network providing an isolation $\geq 18.6 \mathrm{~dB}$ between the $\mathrm{H}$ - and $\mathrm{V}$-ports. The operative bandwidth is from 3.15 to $3.25 \mathrm{GHz}$, and the peak measured gain is approximately $19 \mathrm{dBi}$. The array is suitable for spacecraft operation because of the selected materials, its low-profile ( $\sim 8$ mm thickness), and lightweight. It has potential applications in Synthetic Aperture Radar (SAR), remote sensing, and wireless communications.
\end{abstract}

Index Terms-Microstrip antenna, array, dual polarizations broadband, series-fed.

\section{INTRODUCTION}

$\mathrm{T}$ HERE has been increasing interest in recent years in using S-band frequencies for building the radio system of a Synthetic Aperture Radar (SAR) on spacecraft as opposed to using L- or C-bands. For radar systems on a small spacecraft using low cost launch vehicles, the selection of operating frequency is a compromise. Towards L-band, there is an increasing availability of high power amplifiers and materials to construct antennas, while towards C-band there is higher access capability with regards to the radar incidence angles and opportunity for higher resolution. S-band is therefore a suitable band in between, which provides small, low complexity radars, satisfactory resolution, sufficient sensitivity and enough access capability while also retaining the option of low cost launch vehicles. The antenna design however faces challenges in that an S-band antenna array used on a spacecraft will have fewer radiating elements compared to Cband. This brings challenges to the design of the array antenna using materials suitable for a spacecraft. For SAR applications, the antenna requires dual polarization capability, low-profile, and relatively low cost. The mass of the antenna is also required to be low. Microstrip array antennas are a promising candidate to achieve the requirements of an S-band SAR antenna on a spacecraft. Dual-polarized antennas can be realized by feeding the rectangular microstrip patch at two orthogonal edges, through edge feed or probe feed, which excites transverse magnetic $\mathrm{TM}_{01}$ and $\mathrm{TM}_{10}$ waveguide modes with orthogonal polarization. Both the antenna element itself and its array elements often achieve the isolation of nearly 20 dB [1]. Since the impedance bandwidth depends significantly on the feeding techniques, a maximum of $1.9 \%$ impedance bandwidth can be achieved using probe-fed patches arrays [2], and $15 \%$ with stacked structure [3][4][5].

This work was supported by EADS Astrium Ltd in Portsmouth, UK.

R. Di Bari was with the Surrey Space Centre, Surrey University, Guildford, UK. He is now with the Antennas and Electromagnetic Group at Queen Mary University, London, UK. (Phone: 0044-020-7882-5345, Email: raffaele.dibari@eecs.qmul.ac.uk) T. Brown, S. Gao, and C. Underwood are with the Surrey Space Centre, Surrey University, Guildford, UK. M. Notter, and D. Hall are with EADS Astrium Ltd in Portsmouth, UK.
A coplanar microstrip line structure can achieve $20 \%$ bandwidth for horizontal polarization while vertical polarisation is achieved via a microstrip line through a $\mathrm{H}$ shaped slot [6]. The bandwidth can be extended up to $22 \%$ with proximity coupling [7][8]. For dual-polarized patch arrays with coplanar microstrip feeding network, an impedance bandwidth up to $2 \%$ is achieved if a corporate feeding is employed [1][9]. However, the use of coplanar series as an alternative to corporate feeding has the advantage of a minimum line length feeding network, a compact structure and relatively low cost manufacturing. As a reference, an impedance bandwidth of $1.1 \%$ for standard coplanar series feeding [10] and $2.9 \%$ with line or patch tapering [11][12] has been achieved for single polarization.

In this paper, a novel dual-polarized coplanar series-fed antenna array is designed with materials suitable for spacecraft operations. The basic array geometry is based upon the design originally proposed for the P-Band Biomass antenna, which is found to have good cross-polar element performance for both polarizations and excellent VP/HP port isolation [13]. This work scales the P-Band Biomass antenna to make it operational in the S-band and it extends the number of radiating patches from 2 to 6 , aiming an enhancement of the impedance bandwidth and the radiation characteristics. The requirements are a bandwidth at least $100 \mathrm{MHz}$ (3\%) for both polarizations to enable SAR observations to $\sim 4.5 \mathrm{~m}$ across track resolution incidence angles greater than $20^{\circ}$, and $\sim 3 \mathrm{~m}$ beyond $30^{\circ}$. Once the 6-element sub-array geometry is selected, the beam width specification is dictated by the geometry itself. An aperture populated by such sub-arrays (with identical excitations) has to produce a $\sin (\mathrm{x}) / \mathrm{x}$ or "sinc" type pattern in both planes without grating lobes. The radiation pattern has to be constant along the bandwidth with the maximum gain close to boresight. A gain of approximately 18 $\mathrm{dBi}$ with variations smaller than $3 \mathrm{~dB}$ within the bandwidth was targeted, with Side Lobe Levels (SLLs) less than $-10 \mathrm{~dB}$. The physical feeding point is chosen to be at the antenna end because of mechanical constraints, although a centre feeding design can be envisaged. The prototype antenna including simulated and measured results is presented in this paper.

\section{STRUCTURE OF THE ARRAY ANTENNA}

Fig. 1-a shows the antenna top layer, whose maximum dimensions are $518.08 \times 187.2 \mathrm{~mm}$. It consists of 2 subarrays along the horizontal $\mathrm{x}$ axis, operating in both vertical (VP) and horizontal (HP) linear polarization for the S-band 3.2 GHz. The antenna can work in transmission and receiving modes. The antenna is printed on Kapton LF-9150 sheet and is mounted on a Rohacell foam substrate. The adhesive is a Redux 312 film. 
(a)

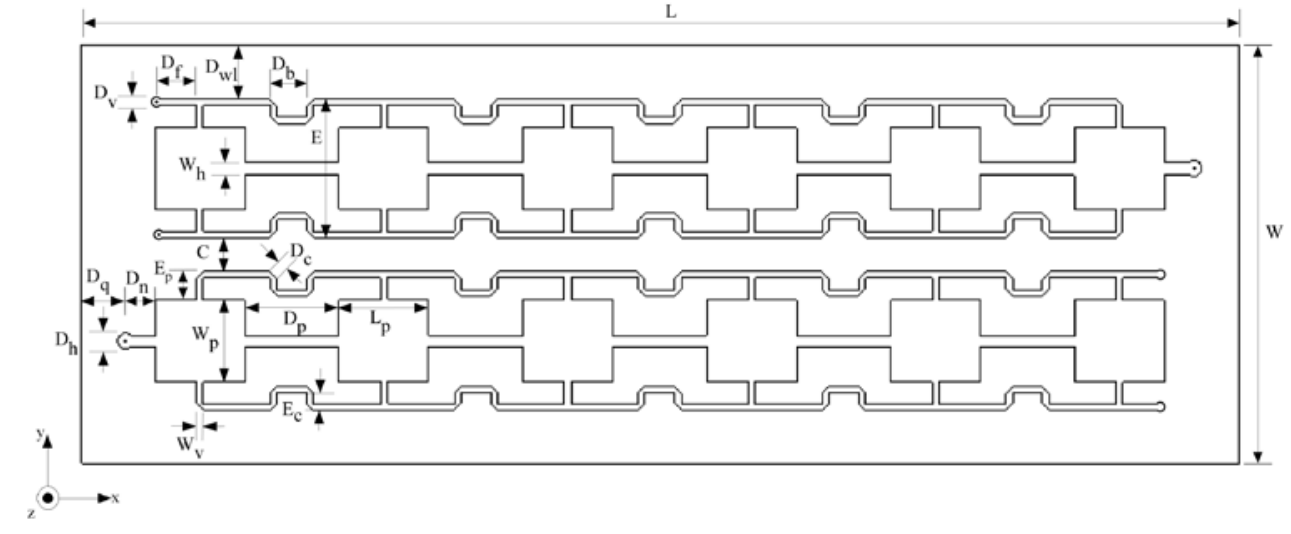

(b)

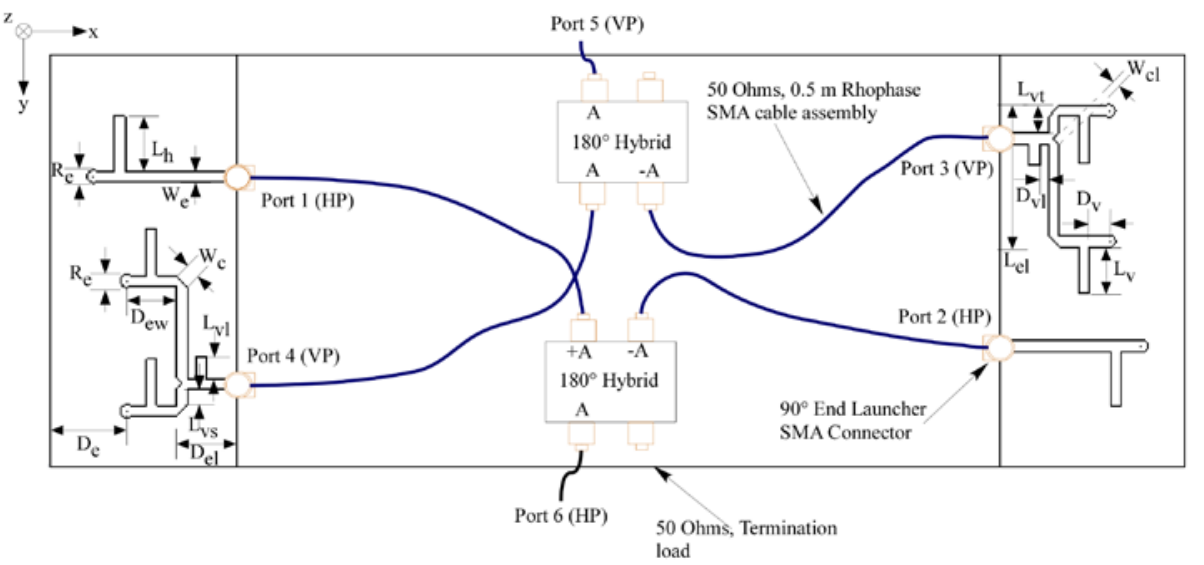

Fig. 1. (a) Layout of the antenna top layer, where $\mathrm{L}=518.08, \mathrm{~W}=187.2, \mathrm{C}=14.95, \mathrm{Wp}=36.57, \mathrm{Lp}=40.12, \mathrm{Dp}=42.2, \mathrm{E}=62.24, \mathrm{Dv}=3.6, \mathrm{Dwl}=23.87, \mathrm{Df}=16.64$, $\mathrm{Ep}=12.83, \mathrm{Ec}=8.19, \mathrm{Wh}=5.09, \mathrm{Dh}=7.07, \mathrm{Dq}=20, \mathrm{Dn}=13.14, \mathrm{Wv}=3, \mathrm{Db}=16.33, \mathrm{Dc}=4.78$. (b) Layout of antenna bottom layer, where $\mathrm{Lh}=24.75, \mathrm{We}=4.86, \mathrm{Lv}=21$, $\mathrm{Re}=5.86, \mathrm{Wc}=7.69, \mathrm{Wcl}=3.43, \mathrm{Dvl}=3.88, \mathrm{Lvl}=9.79$, Lel=64.10, Dv=8.78, Lvs=7.12, Lvt=12.533, De=35.07, Dew=22.75, Del=27.07 (all dimensions are in mm).

TABLE I

Summary of the materials and thicknesses of the antenna layers

\begin{tabular}{ccc}
\hline \hline Layer & $\begin{array}{c}\text { Thickness } \\
{[\mathrm{mm}]}\end{array}$ & Material \\
\hline L1 & 0.034 & Copper $\left(\sigma=5.8 \times 10^{7} \mathrm{~S} / \mathrm{m}\right)$ \\
L 2 & 0.127 & Kapton $\left(\varepsilon_{\mathrm{r}}=3.3, \sigma=0.08 \mathrm{~S} / \mathrm{m}\right)$ \\
L 3 & 0.05 & Adhesive $\left(\varepsilon_{\mathrm{r}}=3.1, \sigma=0.01 \mathrm{~S} / \mathrm{m}\right)$ \\
L 4 & 6 & Rohacell Foam $\left(\varepsilon_{\mathrm{r}}=1.048, \sigma=11 \times 10^{-5} \mathrm{~S} / \mathrm{m}\right)$ \\
L 5 & 0.05 & Adhesive $\left(\varepsilon_{\mathrm{r}}=3.1, \sigma=0.01 \mathrm{~S} / \mathrm{m}\right)$ \\
L 6 & 0.034 & Copper $\left(\sigma=5.8 \times 10^{7} \mathrm{~S} / \mathrm{m}\right)$ \\
L 7 & 0.127 & Kapton $\left(\varepsilon_{\mathrm{r}}=3.3, \sigma=0.08 \mathrm{~S} / \mathrm{m}\right)$ \\
L 8 & 0.05 & Adhesive $\left(\varepsilon_{\mathrm{r}}=3.1, \sigma=0.01 \mathrm{~S} / \mathrm{m}\right)$ \\
L 9 & 0.017 & Copper $\left(\sigma=5.8 \times 10^{7} \mathrm{~S} / \mathrm{m}\right)$ \\
L 10 & 1.6 & Duroid $\left(\varepsilon_{\mathrm{r}}=2.3, \sigma=12 \times 10^{-4} \mathrm{~S} / \mathrm{m}\right)$ \\
L 11 & 0.017 & Copper $\left(\sigma=5.8 \times 10^{7} \mathrm{~S} / \mathrm{m}\right)$ \\
\hline \hline
\end{tabular}

These materials are suitable for spacecraft operations. Table I shows a summary of the materials and thicknesses of the antenna layers. The space between adjacent element centres is $82.2 \mathrm{~mm}$ that equals to $0.88 \lambda_{\mathrm{g}}$ (where $\lambda_{\mathrm{g}}$ is guidedwavelength). The dimensions of the non-resonant patch edges can be calculated using the equation in [14], yielding initial results of $38.5 \mathrm{~mm}$ at $3.2 \mathrm{GHz}$. The optimized values used in the final design are 36.57 and $40.12 \mathrm{~mm}$ for the VP and HP non-resonant edges, respectively. Two microstrip lines, located on the patch edges, are used to excite the patch in orthogonal modes. Fig. 1-b shows the antenna backside where two identical $50 \Omega$ matching networks are attached to the ground plane. A Duroid substrate was required since the dielectric properties of the Rohacell Foam would not allow a
$50 \Omega$ compact design. The matching networks are connected to the antenna feeding ends through $0.8 \mathrm{~mm}$ diameter copper vias. A $90^{\circ}$ end launcher SMA connects the microstrip trace to the coaxial feeding cable. Each cable is $0.5 \mathrm{~m}$ long and connects the $180^{\circ}$ Hybrid power divider to the antenna. Fig. 2 shows the layered structure of the antenna. The layers L6, L7, L8 and L9 have a circular clearance with radius $R_{c}=6.93 \mathrm{~mm}$ around the signal vias. To avoid possible parallel plate wave modes, the two ground planes L6 and L9 are connected to each other with ground vias with $0.4 \mathrm{~mm}$ radius.

\section{DESIGN CONSIDERATION}

A series-fed resonant type array structure is used for each subarray. According preliminary simulations, a 6 elements subarray it expected to maximize the impedance bandwidth. While a standard series-fed configuration is used for the HP feeding, the VP network consists of a symmetric configuration feeding both edges of each patch to improve the field distribution symmetry on the patches and decrease the SLLs. A relatively thick substrate with low permittivity is chosen to increase the impedance bandwidth of microstrip patches. From a mechanical perspective, the substrate should be light, stiff and ideally resistant to compression, since the whole structure needs to be pressured during the adhesive curing process. In this work, a $6 \mathrm{~mm}$ Rohacell $31 \mathrm{HF}$ substrate is chosen for the driven patches and the coplanar feeding network, having a dielectric constant $\varepsilon_{\mathrm{r}}=1.048$. 


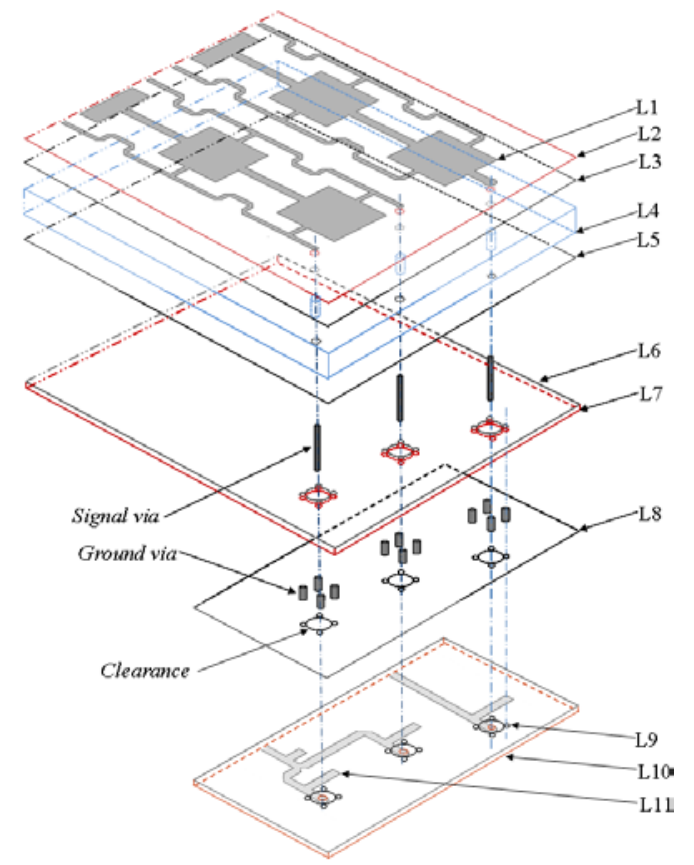

Fig. 2. Exploded view of the antenna

The design approach of this array is carried out by first optimising the single element performance for both polarizations, and then by building up to six-element subarray on an element-by-element basis. At each step, some retuning and tweaking of the feed line geometry was found to be necessary as the effect of element interactions made them felt. Each modelling stage is carried out including the VP $180^{\circ}$ reactive power divider (since the VP feed rails are excited in antiphase). The two sub-arrays are separated in elevation by $77.1 \mathrm{~mm}\left(0.82 \lambda_{0}\right.$ at $\left.3.2 \mathrm{GHz}\right)$. According to simulations, this is the minimum separation required that maintaining good isolation between the VP feed rails and it is critical to the subarray performance. The subarrays have a relative rotation of $180^{\circ}$ to compensate possible pattern squints at the bandwidth edges. Thus the VP and HP subarrays ports are fed with a $180^{\circ}$ Hybrid power divider as shown in Fig. 1-b. Preliminary simulations showed that the dielectric constant of the adhesive layer has a significant impact on the resonant frequency of the microstrip antennas, despite its relative thin thickness. These constants can be altered in uncontrollable way during the high-temperature curing process, since liquid components can be volatilized. As it will be shown in section $\mathrm{IV}$, this aspect of manufacturing will impact on the measured antenna performances.

\section{ANTENNA PROTOTYPE RESULTS}

The antenna performances are simulated and compared with measured results. Simulations are carried out with commercial CST software. The S-parameters are measured by a Vector Network Analyzer, and the far field radiation patterns are measured in an anechoic chamber. The measured loss for the $0.5 \mathrm{~m}$ feeder cable is $\sim 0.5 \mathrm{~dB}$ while the insertion loss for the $180^{\circ}$ hybrid power divider is $\sim 0.6 \mathrm{~dB}$. The end-launcher SMA connector insertion losses are neglected. These values are subtracted from the simulated realized gain for consistency

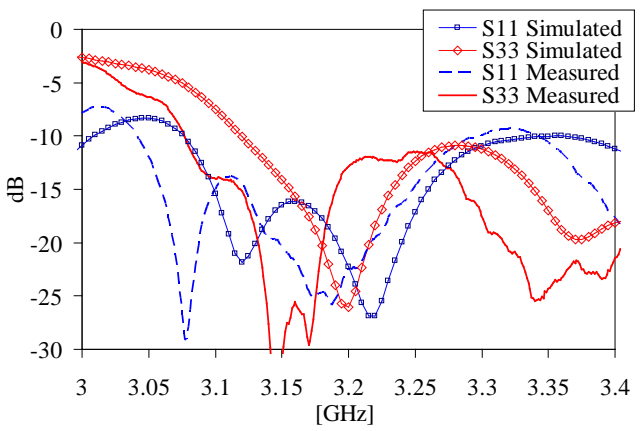

(a)

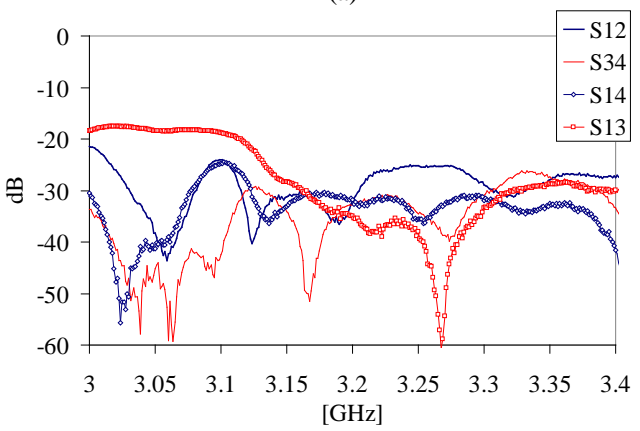

(b)

Fig. 3. (a) Measured and simulated Impedance bandwidth for vertical and horizontal polarization. (b) Measured S-parameters Isolations at the arrays input ports.

with the prototype set-up. In Fig. 3-a, the simulated and measured impedance bandwidth are given. The measured impedance bandwidth is below $-10 \mathrm{~dB}$ within the frequency range of 3.1 to $3.3 \mathrm{GHz}$, corresponding to an impedance bandwidth of $6 \%$. The measured frequencies are shifted down of about $50 \mathrm{MHz}$ compared with the simulated ones, mainly because of the adhesive issues mentioned in section III. A similar adhesive effect has been reported also in [15]. Fig. 3-b shows the isolation between the array input ports. The isolation is at least below $-18.6 \mathrm{~dB}$, within the impedance bandwidth of 3.1 to $3.3 \mathrm{GHz}$. Fig. 4 shows the normalized radiation patterns at $3.2 \mathrm{GHz}$. The measurement radiation patterns are in good agreement with simulations. The measured cross-polarization levels in the E-plane and H-plane are about $15 \mathrm{~dB}$ below the co-polarized beam peaks and they are constant for all frequencies. Table II shows the simulated realized gain, the measured gain at Port 5 and Port 6, and the measured SLLs. A gain of about 17.98 and $17.52 \mathrm{dBi}$ is measured at $3.2 \mathrm{GHz}$ for $\mathrm{VP}$ and $\mathrm{HP}$, respectively. The subarray patterns have a maximum squint of about $\pm 3^{\circ}$ at the impedance bandwidth edges (e.g. 3.1 and $3.3 \mathrm{GHz}$ ) since they are tuned at $3.2 \mathrm{GHz}$. Although the subarrays relative rotation of $180^{\circ}$ fully compensates the squints, the radiation pattern peak powers do not sum perfectly in phase along the boreside direction. This issue would results in a significant loss of gain. compared to the peak gain, such as 14.3 and $10 \mathrm{dBi}$ for simulated and measured gain, respectively. The loss of gain is more severe for the manufactured antenna as the adhesive layers shifted down the resonating frequencies, with consequent radiation pattern degradation and a rising of the subarray pattern squints. The peak SLLs are from -10 to 


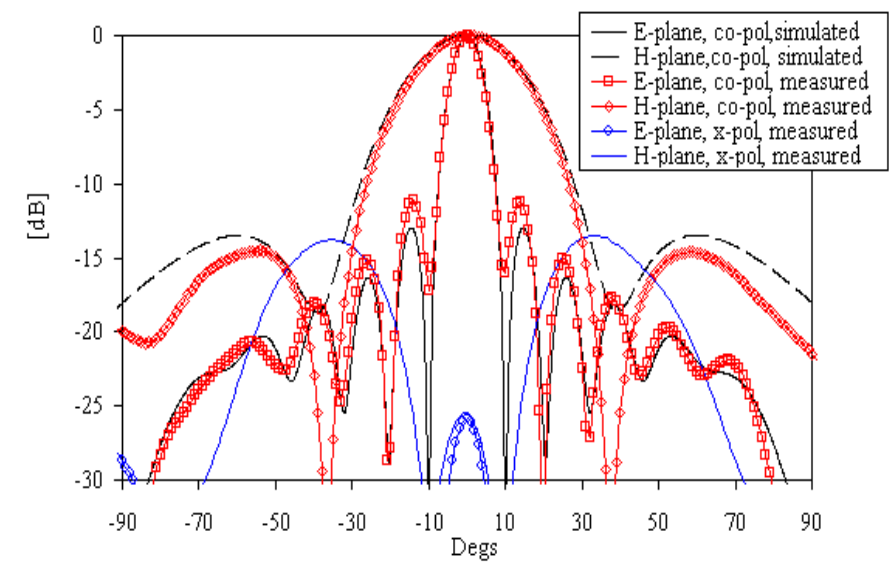

(a)

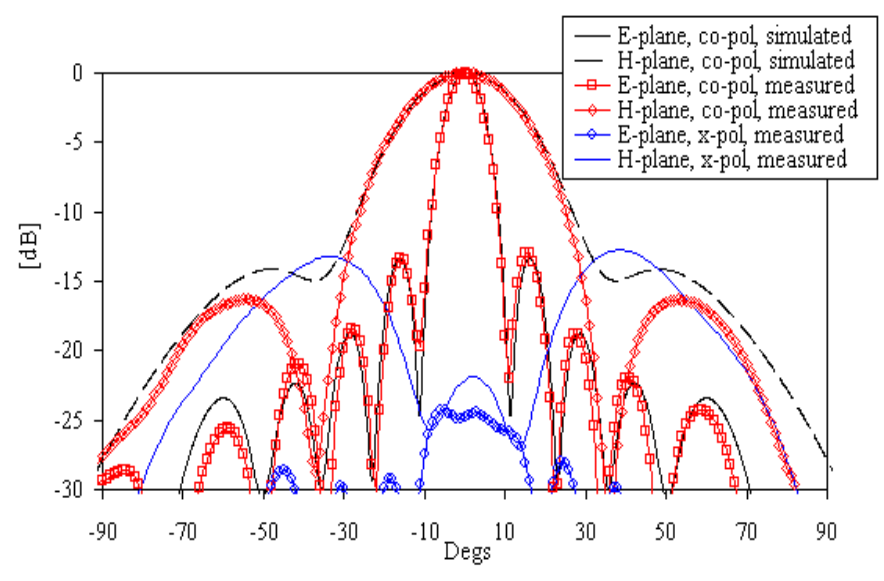

(b)

Fig. 4. Measured and simulated radiation pattern at 3.2 GHz for (a) Port 5 (VP) and (b) Port 6 (HP)

TABLE II

Summary of the simulated (S) realized gain, measured (M) radiation pattern gain for Port 5 and Port 6, and measured SLLs

\begin{tabular}{ccccccc}
\hline \hline $\begin{array}{c}\text { Freq. } \\
{[\mathrm{GHz}]}\end{array}$ & $\begin{array}{c}\text { VP S } \\
{[\mathrm{dBi}]}\end{array}$ & $\begin{array}{c}\text { HP S } \\
{[\mathrm{dBi}]}\end{array}$ & $\begin{array}{c}\text { VP M } \\
{[\mathrm{dBi}]}\end{array}$ & $\begin{array}{c}\text { HP M } \\
{[\mathrm{dBi}]}\end{array}$ & $\begin{array}{c}\text { VP } \\
\text { SLL } \\
{[\mathrm{dB}]}\end{array}$ & $\begin{array}{c}\text { HP } \\
\text { SLL } \\
{[\mathrm{dB}]}\end{array}$ \\
\hline 3.1 & 15.43 & 16.18 & 17.26 & 15.14 & 12.6 & 5.8 \\
3.15 & 16.74 & 15.2 & 19.06 & 17.2 & 12.8 & 10.1 \\
3.2 & 17.66 & 17.9 & 17.98 & 17.52 & 12.95 & 10.6 \\
3.25 & 16.69 & 17.24 & 16.97 & 15.14 & 14.2 & 11.16 \\
3.3 & 14.38 & 14.3 & 14.35 & 10.25 & 13.52 & 11.8 \\
\hline \hline
\end{tabular}

$-14.2 \mathrm{~dB}$ in the range of 3.15 to $3.3 \mathrm{GHz}$ for both polarizations, which are normal for the arrays with a uniform amplitude distribution. The peak SLL of $5.8 \mathrm{~dB}$ at $3.1 \mathrm{GHz}$ for $\mathrm{HP}$ are probably due the spurious radiations from the VP feeding networks. Considering the radiation pattern measured gains and the SLLs, the antenna achieves acceptable measured performances within an operational bandwidth of about 3\%, from the overlay of the impedance and pattern bandwidths.

\section{CONCLUSIONS}

A novel design of the dual-polarized microstrip array antenna is presented with application to S-band SAR with materials and features suitable for spacecraft. The antenna has a simple structure, wide bandwidth and has good isolation between the ports. Considering the adhesive layer properties as an uncontrollable factor in this multilayer structure, it has been difficult to achieve a good matching of the measured performance with simulations. However, the manufactured antenna still presents goods performance in the 3\% operational bandwidth. This antenna is a first step of monolithic array design exercise with larger numbers of rows and several radiating elements per row. Future design work should look at the choice of an adhesive layers to keep excellent bonding properties without the curing processes that affect the dielectric properties.

\section{REFERENCES}

[1] L. J. Du Toit and J. H. Cloete, "Dual polarized linear microstrip patch array," in Proc. IEEE Antennas and Prop. Symp. Dig., 1987, pp. 810-813. [2] J.Granholm, K. Woelders, M. Dich, E.L. Christensen, "Microstrip Antenna for Polarimetric C-band SAR", 1994 Antennas and Propagation Society Int. Symposium, vol. 3, pp. 1844-1847, Seattle, USA.

[3] X.L. Liang, S.S. Zhong, W. Wei, "Dual-polarized corner-fed patch antenna array with high isolation," in Microwave and Optical Technology Letters, vol. 47, issue 6, pp. 520- 522, Oct. 2005

[4] J. Granholm, K. Woelders, "Dual Polarization Stacked Microstrip Patch Antenna Array With Very Low Cross-Polarization,” IEEE Trans. on Antennas and Propagation, vol. 49, no. 10, pp. 1393-1402, Oct. 2001

[5] J. Granholm, N. Skou, "Dual-polarization, wideband microstrip antenna array for airborne C-band SAR", in Proc. International Conf. on Phased Array Systems and Technology, 2000, Dana Point, CA, pp. 243-246 [6] W. Wei, Z. Shun-Shi, L. Xian-Ling, "A dual-polarized stacked microstrip antenna subarray for X-band SAR application”, in Conf. Rec. 2004 IEEE Antennas and Propagation. Society Int. Symposium, vol.2, pp.1603-160, June 2004

[7] E. S. Neves, W. Elmarissi, A. Dreher, "Design of a Broad-Band Low Cross-Polarized X-Band Antenna Array for SAR Applications,” IEEE 2004 AP-S Symposium, vol.3, pp. 2460-2463.

[8] S. Gao and A. Sambell, "Dual-polarized broad-band microstrip antennas fed by proximity coupling," in IEEE Trans. Antenna and Propagation, vol. 53, pp. 526-530, Jan. 2005.

[9] S. Gao and S.S. Zhong, ”A Dual-Polarized Microstrip Antenna Array with High Isolation Fed by Coplanar Network, " in IEEE 1998 Radio and Wireless Conf., pp. 213-216, Colorado Springs, CO , USA

[10] R. A. Sainati, CAD of Microstrip Antennas for Wireless Applications. Boston, MA: Artech House, 1996.

[11] Z. Chen, S. Otto, “A Taper Optimization for Pattern Synthesis of Microstrip Series-Fed Patch Array Antennas”, in Conf. Rec.1009 Wireless Technology Conf., pp. 160-163.

[12] Y. Tao, Y. Ning, and Li Le-Wei, "Novel Series-Fed Taper Antenna Array Design”, Antenna and Wireless Propagation letters, IEEE, vol. 7, no. 4, pp 362-365, July 2008

[13] O. Soykasap, S. Pellegrino, P. Howard , M. Notter, “Tape Spring Large Deployable Antenna," in $47_{\text {th }}$ AIAA/ASME/ASCE/AHS/ASC Structures, Structural Dynamics, and Materials Conf., May 2006 Newport, Rhode Island [14] D.M. Pozar, Microwave engineering, 3rd ed., Wiley, New York, 2005. [15] X. Qu, S. Zhong, Y. Zhang, and W. Wang, "Design of an S/X dual-band dual polarised microstrip antenna array for SAR applications," IET Microwave, Antennas, and Propagations, vol. 1, no. 2, pp.513-517, Apr. 2007" 